\title{
Influence of indium and hydrogen co-doping on optical and electrical properties of zinc oxide thin films deposited by DC magnetron sputtering
}

\author{
Truong Huu Nguyen ${ }^{1}{ }^{*}$, Tinh Van Nguyen ${ }^{1}$, Anh Tuan Thanh Pham ${ }^{1}$, Dung Van Hoang ${ }^{1}$, Hung Minh Vu ${ }^{1}$, \\ Hoi Cong Nguyen ${ }^{1}$, Thang Bach Phan ${ }^{2}$, Vinh Cao Tran ${ }^{1}$
}

${ }^{1}$ Laboratory of Advanced Materials, University of Science, Vietnam National University, Ho Chi Minh City (VNU-HCM)

${ }^{2}$ Center for Innovative Materials and Architectures (INOMAR), Vietnam National University, Ho Chi Minh City (VNU-HCM)

\section{Correspondence}

Truong Huu Nguyen, Laboratory of Advanced Materials, University of Science, Vietnam National University, Ho Chi Minh City (VNU-HCM)

Email: nhtruong@hcmus.edu.vn

\section{History}

- Received: 2019-02-25

- Accepted: 2019-05-28

- Published: 2019-06-25

DOI :

https://doi.org/10.32508/stdj.v22i2.1657

\section{Check for updates}

\section{Copyright}

(c) VNU-HCM Press. This is an openaccess article distributed under the terms of the Creative Commons Attribution 4.0 International license.

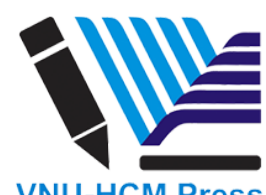

\begin{abstract}
Introduction: ZnO-based thin films, known as potential transparent-conducting oxides (TCO), have still attracted much attention in applications for good-performance electrodes and inner layers in solar cells. Recently, the research tendency has focused on improving carrier mobility rather than carrier concentration to enhance performance and response speed of TCO thin films. In this work, Indium, and Hydrogen co-doped $\mathrm{ZnO}(\mathrm{HIZO})$ thin films were deposited by using DC magnetron sputtering technique in hydrogen-plasma atmosphere. Methods: Indium-doped $\mathrm{ZnO}$ ceramics were used as sputtering targets, in which, Indium content varied from 0.07 to 1.0 at.\%. The electrical, optical, structural and surface morphological properties of the as-deposited films were investigated by using Hall effect-based measurement, UV-Vis spectra, X-ray diffraction (XRD) and fieldemission scanning electron microscopy (FE-SEM), respectively. Results: As a result, the HIZO films sputtered from the 0.1 at.\% In-doped $\mathrm{ZnO}$ target and at $\mathrm{H}_{2} /\left(\mathrm{H}_{2}+\mathrm{Ar}\right)$ ratio of $3.5 \%$ exhibit high electron mobility $\left(47 \mathrm{~cm}^{2} / \mathrm{Ns}\right)$, the lowest resistivity $\left(4.9 \times 10^{-4} \Omega . \mathrm{cm}\right)$ and sheet resistance $(4.7 \Omega / \mathrm{sq}$.$) ,$ simultaneously, high average transmittance $(>80 \%)$ in the visible - near IR spectrum regions. Conclusion: Based on these results, the HIZO films are considered as potential TCO thin films that can be well-used as transparent electrodes in solar cells.
\end{abstract}

Key words: indium and hydrogen co-doped $\mathrm{ZnO}$, magnetron sputtering, TCO thin films, transparent electrodes

\section{INTRODUCTION}

Transparent conducting oxide (TCO) thin films play an essential role in optoelectronic devices. Until now, $\mathrm{Sn}$-doped $\mathrm{In}_{2} \mathrm{O}_{3}$ (ITO) has still been the best TCO with preeminent electrical and optical properties, which used as transparent electrodes. Because of the scarcity of indium, however, it is essential to explore new alternative TCO materials alternative for ITO, which has attracted much attraction of researchers around the world. Based on the potential properties of $\mathrm{ZnO}$ material, the IIIA-group elements (such as $\mathrm{Al}, \mathrm{Ga}, \mathrm{In}$ ) doping into $\mathrm{ZnO}$ thin films can improve the conductivity owing to the increase of carrier concentration ${ }^{1-3}$. On the other hand, the increased carrier concentration often reduces the optical transmittance significantly, especially in the nearIR and IR spectrum regions, due to the free-carrier absorption effect ${ }^{4,5}$. To solve this problem, increasing carrier mobility is expected to be more effective than carrier concentration.

Hydrogen $(\mathrm{H})$ is known as a dopant which can improve carrier mobility of $\mathrm{ZnO}$ films. There have been many studies on $\mathrm{H}$-doped $\mathrm{ZnO}$ films ${ }^{4-8}$, in which, a few of them focused on $\mathrm{H}$ and $\mathrm{In}$ co-doped $\mathrm{ZnO}^{6}$. In the report, however, the limitation is that the carrier concentration was very high, leading to low electron mobility $\left(<30 \mathrm{~cm}^{2} / \mathrm{Vs}\right)$. Therefore, in this work, the combination of In and $\mathrm{H}$ in $\mathrm{ZnO}$ films is expected to obtain high conductivity owing to the moderate freeelectron amount (from In dopant), and good crystalline quality (high mobility due to $\mathrm{H}$ incorporation). We prepare successfully In and $\mathrm{H}$ co-doped $\mathrm{ZnO}$ (HIZO) thin films with low sheet resistance $\left(\mathrm{R}_{S}\right.$ $<5 \Omega$ /sq.), high electron mobility $\left(>40 \mathrm{~cm}^{2} / \mathrm{Vs}\right)$ and high average transmittance $(>80 \%)$ in the wavelength range from $400 \mathrm{~nm}$ to $1100 \mathrm{~nm}$.

\section{MATERIALS \& METHOD}

The ceramic In-doped $\mathrm{ZnO}$ sputtering targets were synthesized by sintering $\mathrm{ZnO}$ and $\mathrm{In}_{2} \mathrm{O}_{3}$ powders at high temperature, which originated from Merck (Germany) and high purity (99.99\%). The compositions of the targets were changed and listed in Table 1. The targets were used to deposit thin films on the glass substrate (Marienfeld, Germany) by using DC mag-

Cite this article : Huu Nguyen T, Van Nguyen T, Thanh Pham A T, Van Hoang D, Minh Vu H, Nguyen H C, Bach Phan T, Cao Tran V. Influence of indium and hydrogen co-doping on optical and electrical properties of zinc oxide thin films deposited by DC magnetron sputtering. Sci. Tech. Dev. J.; 22(2):253257. 
Table 1: The composition of $\mathrm{ZnO}$ sputtering targets with various In content

\begin{tabular}{llllllll}
\hline Targets & A & B & C & D & E & F & G \\
\hline Dopants & 0.07 & 0.1 & 0.15 & 0.3 & 0.5 & 1.0 & 0.0 \\
(at.\% In) & & & & & & & \\
\hline
\end{tabular}

netron sputtering. For preparing HIZO thin films, a small amount of hydrogen gas (5N, SunAir, Singapore) was introduced into the sputtering atmosphere. The added amount of hydrogen was calculated through partial pressure ratio, $\mathrm{H}_{2} /\left(\mathrm{H}_{2}+\mathrm{Ar}\right)$. The substrate temperature and sputtering power were maintained at $100^{\circ} \mathrm{C}$ and $60 \mathrm{~W}$, respectively, while the target-substrate distance was fixed at $5 \mathrm{~cm}$ during the deposition process. At each In content in target, at least three thin films were deposited, so as to ensure repetition and accuracy in properties of the HIZO films.

The thickness of films was about $1000 \mathrm{~nm}$, which was determined by using a Stylus profilometer (Veeco DEKTAK 6M, Korea). The carrier concentration, mobility, resistivity, and sheet resistance of the films were obtained from Hall measurement with Van der Pauw method (Ecopia HMS 3000, Korea) and the four-point probe. X-ray diffraction (BRUKER D8 Advance, US) was used to determine the crystalline structure of the films. The optical spectra were recorded by UV-Vis spectrophotometer (Jasco V-530, Japan) in the wavelength range of $300-1100 \mathrm{~nm}$.

\section{RESULT AND DISCUSSION}

Electrical properties of the HIZO thin films from Hall measurement at room temperature are summarized in Table 2.

Through the electrical properties in Table 2, it is seen that the HIZO films sputtered from the B target at $\mathrm{H}_{2} /\left(\mathrm{H}_{2}+\mathrm{Ar}\right)=3.5 \%$ obtain high electron mobility of $47.0 \mathrm{~cm}^{2} / \mathrm{Vs}$ and the lowest resistivity of $4.9 \times 10^{-4}$ $\Omega . \mathrm{cm}$, which corresponds to the lowest sheet resistance of $4.7 \Omega /$ sq. From these results, the combination of In and $\mathrm{H}$ in $\mathrm{ZnO}$ films initially proposes the significant enhancement in electrical properties of the HIZO films. To evaluate the simultaneous influence of In and $\mathrm{H}$ dopants, the optimum HIZO films are compared to the pure $\mathrm{ZnO}$ films and the IZO films (without $\mathrm{H}$ introduction). The electrical and optical parameters of the three films are listed in Table 3.

Table 3 shows that the carrier concentration of the sample B0 is higher than that of the sample $G$, but lower than that of the sample B. Slassi et al. ${ }^{9}$ and
Khuili et al. ${ }^{10}$ reported that when a $\mathrm{Zn}$ atom is substituted by a IIIA-group atom, the $\mathrm{Al} 3 \mathrm{~s}$, Ga $4 \mathrm{~s}$ or $4 \mathrm{p}$ and In $5 \mathrm{~s}$ orbitals contribute to the occupied states near the Fermi level, which acts as a donor state around the Fermi level. It may be considered as the origin of the increased carrier concentration and electrical conductivity of IIIA group-doped $\mathrm{ZnO}$ films. Furthermore, hydrogen also acts as a source contributing electrons for conduction, with shallow donor states below $\sim 0.03-0.1 \mathrm{eV}$ from the bottom of the conduction band ${ }^{11,12}$. The exciting thing is that the electron mobility of sample $\mathrm{B}$ reaches the highest values of $47.3 \mathrm{~cm}^{2} / \mathrm{Vs}$. This value is considered much higher than that of the other study on HIZO films ${ }^{6}$. The reason can be from the excellent harmony of In and $\mathrm{H}$ dopants in the lattice structure of $\mathrm{ZnO}$ films. To demonstrate this hypothesis, the crystalline structure of the films are investigated through XRD spectra in Figure 1.

From Figure 1, it is seen that all the films only have a prominent $\mathrm{ZnO}$ (002) peak, indicating the typical hexagonal-wurtzite structure of $\mathrm{ZnO}$ material (JCPDS 36-1451). No crystalline phases of In compounds are observed in the X-ray patterns, suggesting that $\mathrm{In}^{3+}$ probably replaces $\mathrm{Zn}^{2+}$ or locates in interstitial sites in $\mathrm{ZnO}$ lattices or segregates in the non-crystalline region at the grain boundaries ${ }^{13}$. The HIZO films (sample B) have the (002) peak with the highest intensity, which indicates that the addition of the small amount of In and $\mathrm{H}$ can give rise to significant improvement in the crystalline quality of $\mathrm{ZnO}$ films. Furthermore, the presence of hydrogen causing the shift of (002) peak in sample B towards lower $2 \theta$ angle as compared to sample $G$ is observed. It suggests the reduction of defects in the crystalline structure of the sample B. Besides, the mean free paths (MFP) of electron in the sample G, sample B0 and sample B $(2.5 \mathrm{~nm}, 3.2 \mathrm{~nm}$ and $7.1 \mathrm{~nm}$, respectively) are much smaller than their crystal size (26.9 nm, 30.4 and 29.6 $\mathrm{nm}$, respectively). Thus, the grain boundary scattering cannot be the dominant mechanism affecting the electron mobility. The increase in mobility value, as shown in Table 3, therefore, can be due to the decrease in ionized impurities scattering.

In literature, hydrogen can support $\operatorname{In}^{3+}$ substituting into $\mathrm{Zn}^{2+}$ sites due to charge neutrality. The replacement acts an essential role in increasing $\mathrm{In}^{3+}$ donors, which can be realized from the shift of (002) peak, as mentioned in XRD patterns. As a result, the reduction of scattering centers relating to interstitial impurities, which leads to increase the mobility. Furthermore, hydrogen can passivate some defects in the crystalline 
Table 2: Carrier concentration (n), electron mobility $(\mu)$, resistivity $(\rho)$ and sheet resistance $\left(\mathbf{R}_{S}\right)$ of the HIZO films

\begin{tabular}{llllll}
\hline $\begin{array}{l}\text { Films deposited } \\
\text { from targets }\end{array}$ & $\begin{array}{l}\mathbf{H}_{2} /\left(\mathbf{H}_{2}+\mathbf{A r}\right) \\
(\%)\end{array}$ & $\begin{array}{l}\mathbf{n} \\
\left(\mathbf{1 0}^{20} \mathbf{c m}^{-3}\right)\end{array}$ & $\begin{array}{l}\boldsymbol{\mu} \\
\left(\mathbf{c m}^{2} / \mathbf{V s}\right)\end{array}$ & $\begin{array}{l}\rho \\
(\mathbf{1 0}\end{array}$ & $\begin{array}{l}\mathbf{R}_{S} \\
(\Omega / \mathbf{c m})\end{array}$ \\
\hline A & 1.9 & 49.1 & 6.8 & 6.6 \\
B & 2.7 & 47.3 & 4.9 & 4.7 \\
C & & 43.4 & 6.2 & 6.0 \\
D & 2.3 & 36.1 & 6.7 & 6.5 \\
E & 2.6 & 21.7 & 7.3 & 7.2 \\
F & 3.5 & 3.9 & 27.0 & 7.7 & 7.4 \\
\hline
\end{tabular}

Table 3: Carrier concentration $(\mathbf{n})$, electron mobility $(\mu)$, resistivity $(\rho)$, sheet resistance $\left(\mathbf{R}_{S}\right)$, and average transmittance in the visible ( $\mathrm{T}_{V i s}$ ) and the near IR regions of the $\mathrm{ZnO}$ (sample $\mathrm{G}$ ), IZO (sample BO) and HIZO (sample B) films

\begin{tabular}{llllllll}
\hline $\begin{array}{l}\text { Sam- } \\
\text { ples }\end{array}$ & $\begin{array}{l}\mathbf{H}_{2} /\left(\mathbf{H}_{2}+\mathrm{Ar}\right) \\
(\%)\end{array}$ & $\begin{array}{l}\mathbf{n}\left(\mathbf{x} \mathbf{1 0}^{20}\right. \\
\left.\mathbf{c m}^{-3}\right)\end{array}$ & $\mu\left(\mathbf{c m}^{2} / \mathbf{V s}\right)$ & $\begin{array}{l}\rho\left(\mathbf{1 0}^{-4}\right. \\
\Omega . \mathbf{c m})\end{array}$ & $\mathrm{R}_{\mathrm{S}}(\Omega / \mathbf{s q})$. & $\mathrm{T}_{\mathrm{Vis}_{\text {is }}}(\%)$ & $\mathrm{T}_{\mathrm{NIR}}(\%)$ \\
\hline $\mathrm{G}$ & 0 & 0.7 & 30.1 & 28.3 & 27.8 & 80.5 & 82.8 \\
$\mathrm{~B} 0$ & 0 & 1.2 & 32.1 & 15.9 & 14.6 & 78.1 & 79.1 \\
$\mathrm{~B}$ & 3.5 & 2.7 & 47.3 & 4.9 & 4.7 & 81.5 & 82.0 \\
\hline
\end{tabular}
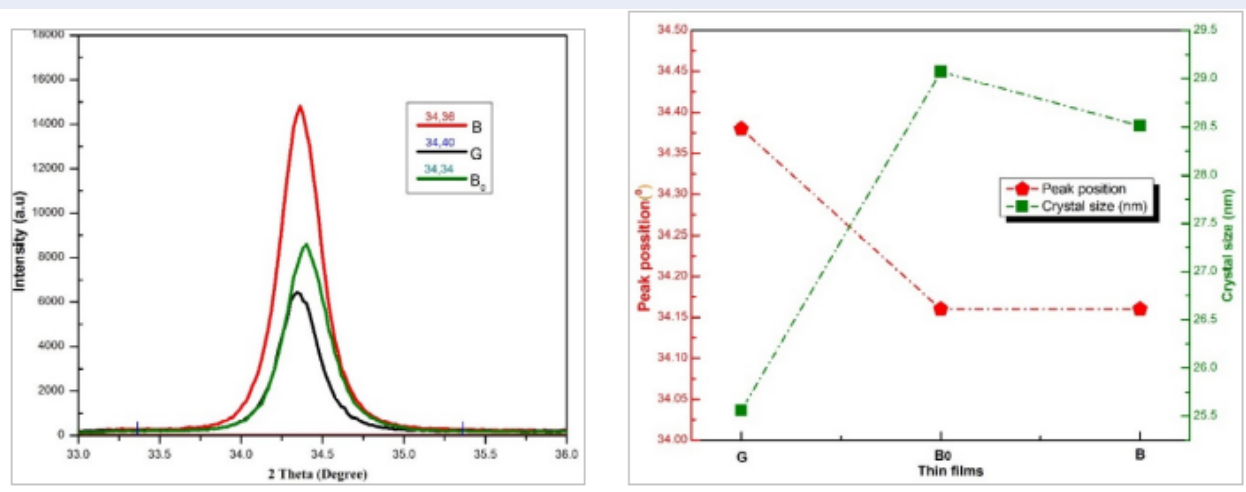

Figure 1: X-ray diffraction patterns (left) and variations in peak position and crystal size of the ZnO, IZO and HIZO films (right).

structure of $\mathrm{ZnO}$, such as zinc vacancies $\left(\mathrm{V}_{\mathrm{Zn}}\right)$, dangling bonds ${ }^{6-8}$. This hydrogen passivation can occur through the adsorption and bonding formation of $\mathrm{O}-\mathrm{H}, \mathrm{Zn}-\mathrm{H}$, or $\mathrm{Zn}-\mathrm{OH}$ in crystalline grains, grain boundaries, and film's surface of $\mathrm{ZnO}$ films ${ }^{6}$.

During the deposition process, the effect of hydrogen on the electrical properties, especially on the mobility of the films can be observed. Another reason may be the etching phenomenon in hydrogen plasma producing excited hydrogen atoms ${ }^{14}$. These excited $\mathrm{H}$ atoms can make bonds with $\mathrm{O}$ atoms leading to the lack of $\mathrm{O}$ atoms, which increases the number of $\mathrm{O}$ vacancies and interstitial $\mathrm{Zn}$. Therefore, the control of hydrogen pressure is also the most important factor deciding the electrical and structural properties of the HIZO thin films.

Figure 2 illustrates the surface morphology of the $\mathrm{ZnO}$, IZO, and HIZO thin films. It is seen that the grain density of sample $\mathrm{B}$ seems to be highest, while the sample $G$ has the lowest value. This is entirely consistent with the improvement in the crystalline structure and electrical properties of the films, as discussed in the XRD (Figure 1) and Hall measurement (Tables 2 and 3) results. Additionally, in sample B, the density of black spots tends to decrease. It is possible that $\mathrm{In}^{3+}$ ions can insert into the $\mathrm{Zn}$ vacancies. 

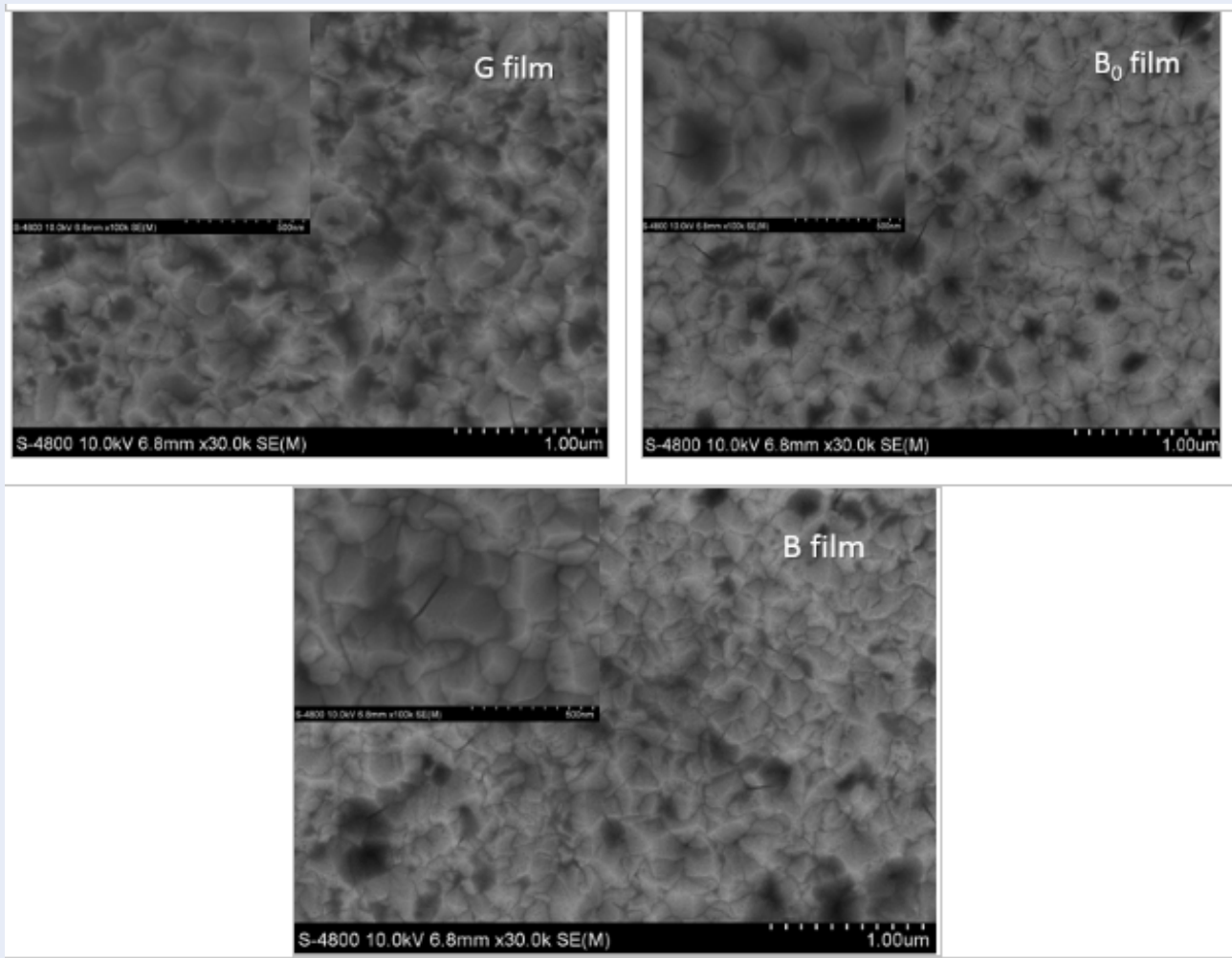

Figure 2: FE-SEM images of the G, BO and B samples.

Simultaneously, $\mathrm{H}^{+}$ions also fill up with $\mathrm{O}$ vacancies and the black spots are enlarged at the grain boundaries. This suggests that $\mathrm{H}^{+}$ions have been linked to $\mathrm{O}^{2-}$ ions at the surface, which removes small particles from the surface of thin films ${ }^{15}$.

As mentioned in Table 3 and Figure 3, 1000-nmthick sample B has the lowest sheet resistance of 4.7 $\Omega /$ sq. and high average transmission over $80 \%$ in the Vis -NIR region, which can be well used as transparent electrodes for solar cells.

\section{CONCLUSION}

A small amount of 0.1 at.\% In-mixed $\mathrm{ZnO}$ sputtering target and sputtering in hydrogen plasma are the optimum conditions for depositing good-performance $\mathrm{ZnO}$ thin films. The carrier concentration increases significantly from 0.7 to $2.7 \times 10^{20} \mathrm{~cm}^{-3}$ due to In donors. The electron mobility enhances by $67 \%$, thanks to the reasonable hydrogen ratio (3.5\%). As a result, the sheet resistance also decreases by $83 \%$ from 27.8 to $4.7 \Omega /$ sq. Through this work, we propose that the HIZO films can be used as transparent electrodes in low-temperature applications $\left(100^{\circ} \mathrm{C}\right)$.

\section{ABBREVIATIONS}

DC: Direct Current
TCO: Transparent Conducting Oxides

MFP: Mean Free Paths

ITO: $\mathrm{Sn}$-doped $\mathrm{In}_{2} \mathrm{O}_{3}$

XRD: X - Ray Diffraction

$\mathbf{V}_{Z n}$ : Zinc Vacancy

FE-SEM: Field Emission Scanning electron Microscopy

Vis-NIR: Visible and Near Infrared Range

\section{COMPETING INTERESTS}

The authors declare no competing interests.

\section{AUTHORS' CONTRIBUTIONS}

Truong Huu Nguyen researched and wrote the paper. Vinh Cao Tran designed the study. Tinh Van Nguyen, Anh Tuan Thanh Pham, Dung Van Hoang, Hung Minh Vu, Hoi Cong Nguyen conducted the experiments. Bach Thang Phan help to revise the manuscript.

\section{ACKNOWLEDGMENTS}

The University of Science funded this research Vietnam National University, Ho Chi Minh City (VNU-HCM) under Grant number T49-2017. 


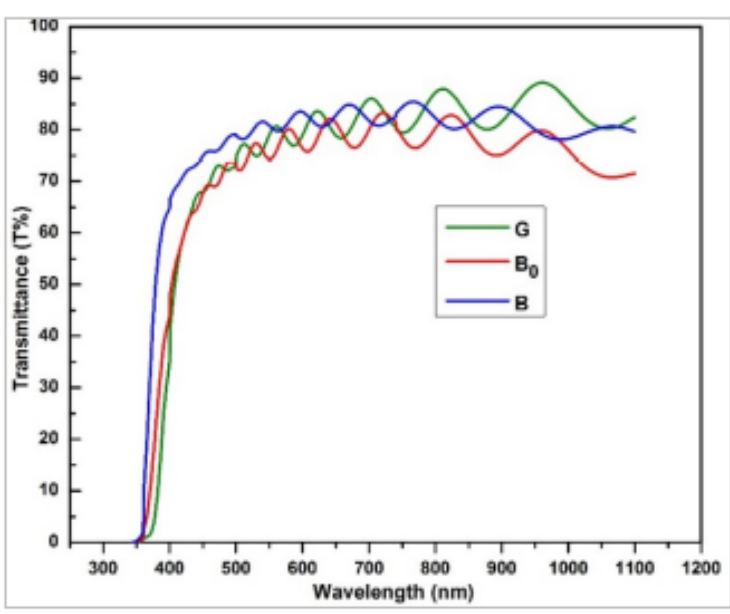

Figure 3: Optical transmittance spectra of the G, B0 and B films.

The authors would like to thank the professors, reviewers, and technical committee of the Journal help us to upgrade the quality of this paper.

\section{REFERENCES}

1. Peng LP. Characteristics of ZnO:In thin Ims prepared by RF magnetron sputtering. Physical E. 2009;41:1819-1823. Available from: 10.1016/j.physe.2009.07.006.

2. Jung K. Infuence of substrate temperature on the electrical and optical properties of Ga-doped $\mathrm{ZnO}$ thin films fabricated by continuous composition spread. Ceramics International. 2012;38S:S605-S608. Available from: 10.1016/j.ceramint.2011. 05.107.

3. Tubtimtae A, Lee MW. ZnO nanorods on undoped and indium doped $\mathrm{ZnO}$ thin films as a TCO layer on nonconductive glass for dye-sensitized solar cells. Superlattices and Microstructures. 2012;52:987-996. Available from: 10.1016/j.spmi.2012. 08.002 .

4. Macco B, Knoops HCM, Verheijen MA, Beyer W, Creatore M, Kessels WMM. Atomic layer deposition of high mobility hydrogen doped zinc oxide" Solar Energy Material and Solar cell", online 25.5.2017. 2017; Available from: 10.1016/j.solmat.2017. 05.040 .

5. Dung HV, Khanh ND, Vinh TC. Deposition of high electron mobility transparent conducting aluminium doped zinc oxide thin films by dc magnetron sputtering . Journal of Science and Technology Vietnam. 2015;Available from: 10. 15625/2525-2518/54/1A/11821.

6. Singh A. On the temperature dependence of mobility in hydrogenated indium doped $\mathrm{ZnO}$ thin films. Acta Materialia. 2014;77:125-132. Available from: 10.1016/j.actamat.2014.05. 048.

7. Polyakov AY. Hydrogen plasma treatment effects on electrical and optical properties of $\mathrm{n}-\mathrm{ZnO}$. Journal of Applied Physics.
2003;94:400. Available from: 10.1063/1.1579114.

8. Koch SG, et al. Interplay between interstitial and substitutional hydrogen donors in $\mathrm{ZnO}$. Physical Review B. 2014;89:235203. Available from: 10.1103/PhysRevB.89. 235203.

9. Slassi A, Naji S, Benyoussef A, Hamedoun M, Kenz AE. On the transparent conducting oxide Al doped ZnO: First Principles and Boltzmann equations study. J Alloy Compd. 2014;605:118-123. Available from: 10.1063/1.1586977.

10. Khuili M, Fazouan N, Makarim HAE, Halani GE, Atmani EH. Comparative first principles study of $\mathrm{ZnO}$ doped with group III elements. J Alloy Compd. 2016;688:368-375. Available from: 10.1016/j.spmi.2012.03.012.

11. Willander M, Nur O, Sadaf JR, Qadir MI, Zaman S, Zainelabdin A, et al. Luminescence from Zinc Oxide Nanostructures and Polymers and their Hybrid Devices. Materials. 2010;3:26432667. Available from: 10.1016/j.apsusc.2009.06.083.

12. Akazawa $\mathrm{H}$. Hydrogen induced electric conduction in undoped $\mathrm{ZnO}$ and Ga-doped $\mathrm{ZnO}$ thin films: Creating native donors via reduction, hydrogen donors, and reactivating extrinsic donors. J Vac Sci Technol A: Vacuum, Surfaces, and Film. 2014;32:051511. Available from: 10.1016/j.jallcom.2014. 03.177.

13. Ko YD, Kim KC, Kim YS. Effects of substrate temperature on the Ga-doped $\mathrm{ZnO}$ films as an anode material of organic light emitting diodes. Superlattices and Microstructures. 2012;51(6):933-941. Available from: 10.1016/j.jallcom.2016. 06.294 .

14. Wang $L$, et al. Temperature dependence of the free-exciton transition energy in zinc oxide by photoluminescence excitation spectroscopy. Journal of Applied Physics. 2003;94:973978. Available from: $10.3390 / \mathrm{ma} 3042643$.

15. Park YR, et al. Effect of hydrogen doping in $\mathrm{ZnO}$ thin films by pulsed DC magnetron sputtering. Applied Surface Sciences. 2009;255:9010-9014. Available from: 10.1116/1.4892777. 